\title{
Serum protein levels following surgery in breast cancer patients: A protein microarray approach
}

\author{
LUIS G. PEREZ-RIVAS ${ }^{1}$, JOSE M. JEREZ ${ }^{2}$, CRISTINA E. FERNANDEZ-DE SOUSA ${ }^{1}$, \\ VANESSA DE LUQUE $^{1}$, CRISTINA QUERO ${ }^{1}$, BELLA PAJARES $^{1}$, LEONARDO FRANCO $^{2}$, \\ ALFONSO SANCHEZ-MUNOOZ $^{1}$, NURIA RIBELLES ${ }^{1}$ and EMILIO ALBA ${ }^{1}$
}

${ }^{1}$ Department of Medical Oncology, Hospital Universitario Virgen de la Victoria, Campus de Teatinos s/n, 29010 Malaga;

${ }^{2}$ Department of Languages and Computer Science, University of Malaga, Campus de Teatinos s/n, 29071 Malaga, Spain

Received May 17, 2012; Accepted July 30, 2012

DOI: 10.3892/ijo.2012.1667

\begin{abstract}
Surgery is the primary treatment for non-metastatic breast cancer. However, the risk of early recurrence remains after surgical removal of the primary tumor. Recurrence is suggested to result from hidden micrometastatic foci, which are triggered to escape from dormancy by surgical resection of the primary tumor. In this study, we focused on the differential impact of breast surgery on the serum profiles of early breast cancer patients and healthy women. Serum samples from invasive breast cancer patients, in situ carcinoma breast cancer patients and healthy women were analyzed using reverse phase protein array technology. Samples were collected prior to breast surgery and $24 \mathrm{~h}$ following breast surgery. Both the expression level and the velocity of 42 serum proteins were quantified and compared among groups. We found that surgery increased the concentration of several proteins (CSF1, THSB2, IL6, IL7, IL16, FasL and VEGF-B) in the overall population. Compared with healthy women and patients with non-invasive tumors, invasive tumor patients exhibited higher preoperative levels of several serum proteins, such as $\alpha$ FP, IFN $\beta 1$, VEGF-A, IL18, E-cadherin or CD31, and lower postoperative levels of TNF $\alpha$ and IL5. Similarly, we detected significant surgery-induced changes in the velocity of VEGF-A and IL16 accumulation in samples derived from invasive breast cancer patients. In conclusion, breast surgery induced distinct changes in the concentrations and dynamics of serum proteins in invasive breast cancer patients compared with healthy women and noninvasive tumor patients.
\end{abstract}

Correspondence to: Professor Emilio Alba, Department of Medical Oncology, Hospital Universitario Virgen de la Victoria, Campus de Teatinos s/n, 29010 Malaga, Spain

E-mail: ealbac@uma.es

Abbreviations: $\alpha \mathrm{FP}, \alpha$-fetoprotein; CTS D, cathepsin D; E-cad, E-cadherin; ENG, endoglin; FasL, Fas ligand; HSA, human serum albumin; IFN, interferon; OPN, osteopontin; RRPA, reverse phase protein array; THBS, thrombospondin; VWF, von Willebrand factor

Key words: breast cancer, surgery, reverse phase protein array, serum protein profile, dormancy

\section{Introduction}

Breast cancer is the most common type of cancer diagnosed in women and the leading cause of female cancer-related mortality worldwide (1). Breast cancer is currently considered a heterogeneous disease that includes multiple subtypes that differ in origin, dynamics, response to treatments, risk of recurrence and survival (2-5).

Surgery is the primary therapeutic option for treating breast cancer and other solid neoplasms. However, surgical treatment alone is often insufficient to eradicate the disease since most patients develop distant tumors that were present as undetectable micrometastases at the time of diagnosis, keeping a higher risk of recurrence after tumor removal. Furthermore, although surgery results in a considerable increase in overall survival for most patients, evidence suggests that tumor removal may unfavorably alter the natural history of the disease. Based on preclinical models and the analysis of large series of patients, several authors have postulated a link between surgery and recurrence (6-9). This hypothesis is supported by the existence of a nonproliferative, dormant state of distal micrometastatic foci that can be disrupted after the surgical depletion of the primary tumor (10-12). Surgery-driven escape from dormancy is proposed to be a systemic process mediated by soluble secreted proteins, such as growth factors, chemokines or angiogenic factors, that also play a critical role in wound healing and tissue regeneration following surgery $(13,14)$.

Changes in the concentration of serum proteins have traditionally been measured by techniques based on highly sensitive and specific antibody-antigen recognition, such as ELISA, RIA or western blot analysis. Nevertheless, these techniques are suitable for the quantification of only a single or a few analytes per assay. The development of automated, high-throughput technologies in the field of molecular biology has provided substantial advances in the understanding of disease processes by enabling the evaluation of a large number of samples in a single assay (15). Reverse phase protein microarrays (RPPA) are high-throughput, multiplexed and miniaturized immunoassays in which a small volume of protein samples is spotted onto a capturing surface and probed with an antibody directed against the analyte of interest (16-18). Thus, RPPAs 
enable the mass detection of molecules and reduce cost, time and sample volume without altering sensitivity or specificity. These properties have made RPPAs a powerful tool in cancer research (19).

The main aim of the present study was to detect variations in serum protein levels that directly result from breast surgery, focusing on those changes specifically induced by surgery in patients with invasive breast cancer. We employed RPPAs to examine the expression levels of 42 soluble proteins in serum samples from healthy controls and breast cancer patients, both before and after breast surgery.

\section{Materials and methods}

Sample preparation. Serum samples were obtained from 79 women who underwent surgery at the Hospital Universitario Virgen de la Victoria (Malaga, Spain) in our hospital between 1998 and 2005. All subjects provided informed consent for study inclusion. Among the patients, 56 were diagnosed with invasive breast cancer and 7 were diagnosed with in situ breast carcinoma. Sixteen women who developed benign breast fibroadenoma were included as healthy controls. None of the patients received adjuvant chemotherapy before surgery or immediate breast reconstruction after mastectomy. Samples were collected $8 \mathrm{~h}$ before surgery, denoted $\mathrm{t}(0)$, and $24 \mathrm{~h}$ after mastectomy/lumpectomy, denoted $\mathrm{t}(24)$. Blood was collected in $3 \mathrm{ml}$ serum-separating tubes (SST, BectonDickinson, Franklin Lakes, NJ, USA) and processed within $1 \mathrm{~h}$ after collection. Samples were left at room temperature for 30-40 min until clotted. Serum was obtained by centrifugation at $4,000 \mathrm{rpm}$ for $10 \mathrm{~min}$ at $4^{\circ} \mathrm{C}$ and stored in $200 \mu \mathrm{l}$ aliquots at $-80^{\circ} \mathrm{C}$ until use. The study was approved by our hospital's ethics committee.

Antibodies. A set of 45 polyclonal antibodies raised against 42 different serum soluble proteins was used to probe the RPPAs (SDI Inc, Newark, DE, USA; Table II). The human serum albumin level was determined on each spot using a monoclonal $\alpha$-HSA antibody (Sigma-Aldrich, St. Gallen, Switzerland) and served as an intra-spot normalization control. Two different fluorescent-labeled secondary antibodies were used: a donkey $\alpha$-mouse IgG-DyLight649 and a goat $\alpha$-rabbit IgG-Cy3 (Jackson Immunoresearch, Suffolk, UK).

Microarray generation. Serum samples were diluted in Denaturing Printing Buffer (DPB) at a final concentration of $8 \%$ glycerol, $2 \% \mathrm{SDS}, 50 \mathrm{mM}$ Tris- $\mathrm{HCl}, \mathrm{pH} 6.8$ and $2 \% \beta$-ME, as previously described (20), loaded onto 384-well plates and denatured by boiling at $95^{\circ} \mathrm{C}$ for $10 \mathrm{~min}$. Ten picoliters from each sample were spotted onto low-fluorescence Immobilon-FL membranes (Merck Millipore, Darmstadt, Germany) using a BioOdyssey Calligrapher MiniArrayer (Bio-Rad, Hercules, CA, USA). Spots were printed in duplicate on each membrane following a predefined $24 \times 24$ matrix pattern and dried for $2 \mathrm{~h}$ inside the printer. Subsequently, the membranes were stored at $4^{\circ} \mathrm{C}$ in a desiccated chamber with $\mathrm{NaCl}$. Prior to use, membranes were stained with Ponceau red solution (AppliChem, Darmstadt, Germany) to ensure that the spots were printed successfully. The membranes were then washed once with double-distilled water and twice with TBS-T (50 mM Tris- $\mathrm{HCl}, \mathrm{pH}$ 7.5, $150 \mathrm{mM} \mathrm{NaCl}$, $0.1 \%$ Tween-20) and blocked with blocking buffer (3\% bovine serum albumin in TBS-T) for $30 \mathrm{~min}$ at room temperature. Next, the membranes were incubated for $1 \mathrm{~h}$ at room temperature in blocking buffer containing both the specific primary antibody and the HSA antibody used for normalization. After three washes in TBS-T, membranes were incubated for $30 \mathrm{~min}$ at room temperature in blocking buffer containing both fluorescent-labeled secondary antibodies. The membranes were washed three times in TBS-T and once in double-distilled water and then air-dried in darkness. Finally, fluorescence levels were quantified in a LuxScan 10K/A fluorescence scanner (CapitalBio, Beijing, China) at $570 \mathrm{~nm}$ for the Cy3-labeled specific protein of interest and $670 \mathrm{~nm}$ for the DyLight649-labeled HSA.

To perform robust inter-array comparisons, we referenced the raw fluorescence data from the protein of interest (green) to the level of endogenous human albumin (red) in each spot. This approach also enabled us to discriminate between specific variations and fluctuations related to surgery-associated protein leakage and stress, as previously described (21).

Data analysis. The complete analysis of microarray data was performed using the R programming language (http://www.rproject.org), which has become a de facto standard in the field. Foreground and background intensities from scanned images were extracted using data input functions for twocolor microarrays in the limma package (22). The background intensities were subtracted from the foreground intensities for each spot on the arrays, and then a quantile normalization procedure was implemented to make intensities consistent between arrays. Quantile normalization was proposed by Yang and Thorne (23) for two-color cDNA arrays, with the aim of ensuring that the intensities have the same empirical distribution across arrays and across channels. The values of replicate spots within each array were then replaced with their average values.

Multiple linear models were fitted to the expression data (in log-ratio scale) for each antibody. Thus, the coefficients of the fitted models describe the differences between the sources hybridized to the arrays. Assessment of differential expression was then completed by performing hypothesis tests and adjusting the $\mathrm{p}$-values for multiple tests. The basic statistical method used to determine significance was the moderated $\mathrm{t}$ statistic, which is computed for each probe and for each contrast using a simple Bayesian model that borrows information from the ensemble of antibodies to aid with inference for each individual antibody (24). The method of Benjamini and Hochberg (25) was used to control the false discovery rate and adjust for q-values such that all antibodies with a q-value below a threshold (typically 0.05 ) were selected as differentially expressed.

\section{Results}

To measure the impact of surgery on the serum protein profile, we designed a longitudinal study with serum samples obtained from 63 breast cancer patients who underwent breast surgery at the Hospital Universitario Virgen de la Victoria in Malaga. 
Table I. Characteristics of the study population.

\begin{tabular}{|c|c|c|c|}
\hline & Invasive & In situ & Control \\
\hline $\begin{array}{l}\text { Mean age, years } \\
\text { (range) }\end{array}$ & $58(27-87)$ & $54(45-74)$ & $36(18-55)$ \\
\hline \multicolumn{4}{|l|}{ Hormonal status } \\
\hline Premenopausal & 22 & 3 & 14 \\
\hline Postmenopausal & 24 & 4 & 2 \\
\hline \multicolumn{4}{|l|}{ Surgery } \\
\hline Mastectomy & 30 & 1 & - \\
\hline Breast conserving & 26 & 6 & 16 \\
\hline \multicolumn{4}{|l|}{ Tumor size } \\
\hline $\mathrm{T} 1(<2 \mathrm{~cm})$ & 20 & & \\
\hline $\mathrm{T} 2(2-5 \mathrm{~cm})$ & 32 & & \\
\hline $\mathrm{T} 3(>5 \mathrm{~cm})$ & 2 & & \\
\hline NA & 2 & & \\
\hline \multicolumn{4}{|l|}{ Tumor grade } \\
\hline I & 10 & & \\
\hline II & 31 & & \\
\hline III & 13 & & \\
\hline NA & 2 & & \\
\hline \multicolumn{4}{|l|}{ ER expression } \\
\hline Negative & 16 & & \\
\hline Positive & 40 & & \\
\hline \multicolumn{4}{|l|}{ PgR expression } \\
\hline Negative & 16 & & \\
\hline Positive & 40 & & \\
\hline \multicolumn{4}{|l|}{ HER2 status } \\
\hline Negative & 35 & & \\
\hline Positive & 13 & & \\
\hline NA & 8 & & \\
\hline \multicolumn{4}{|l|}{ Nodal status } \\
\hline Negative & 26 & & \\
\hline Positive & 25 & & \\
\hline NA & 5 & & \\
\hline
\end{tabular}

To provide a control set, we collected samples from 16 healthy women who underwent operations for fibroadenoma. The clinical characteristics of patients and controls are detailed in Table I. Samples were obtained prior to surgery, denoted $t(0)$, and $24 \mathrm{~h}$ after the operation, denoted $\mathrm{t}(24)$, to prevent potential interference from uncontrolled factors, such as diet, postsurgical infections or adjuvant treatment. Variations in serum protein levels were quantified using reverse phase protein arrays (RPPAs) and a set of 45 antibodies raised against 42 proteins involved in angiogenesis, proliferation, apoptosis, inflammation or wound healing (Table II). A representative image of a hybridized array is shown in Fig. 1.

Mean levels of each antigen were calculated and represented as a heat map (Fig. 2). Surgery-induced changes in the protein profiles of invasive breast cancer patients (I), in situ breast cancer patients (S) and fibroadenoma control subjects (B) were examined, with a particular focus on
Table II. List of antibodies used in the study.

\begin{tabular}{lcccc}
\hline \multicolumn{5}{c}{ Antibodies } \\
\hline$\alpha$ FP & ENG & IFN $\gamma$ & IL18 & PDGF-B \\
CD31 & Factor XIIIa & IL1A & IL24 & THBS2 \\
CD44 & FasL (A) & IL1B & MMP1 & THBS3 \\
CEACAM & FasL (B) & IL5 & MMP11 & TNF \\
CSF1 & HER2 & IL6 & MMP3 & VCAM1(A) \\
CSF2 & HER3 & IL6ST & MMP7 & VCAM1(B) \\
CTS D & ICAM5 & IL7 & MMP9 & VEGF-A \\
E-Cad (A) & IFN 11 & IL12A & MUC16 & VEGF-B \\
E-Cad (B) & IFN 31 & IL16 & OPN & VWF \\
\hline
\end{tabular}

common changes and specific differences that occurred among the different groups of patients. Several cytokines (CSF1, IL6, IL7 and IL16) and angiogenesis-related factors (THBS2 and VEGF-B) were consistently increased after surgery in the overall population (Table III), suggesting that these proteins are involved in a common response to surgical injury in both breast cancer patients and healthy women. However, we identified several proteins that were differentially expressed in B samples before and after surgery (Fig. 2, red asterisks), most of which were angiogenic factors; the concentrations of these proteins were higher in samples collected after the surgical removal of the primary tumor than in preoperative samples. Markedly, we discovered that $\mathrm{S}$ and I samples were grouped based on the expression of this same set of proteins. S samples clustered with preoperative B samples whereas I samples clustered with postoperative B samples, regardless of surgery.

Since most relapses are caused by invasive tumors, we focused on specific differences between I and B or between I and $\mathrm{nI}$ (noninvasive disease, which includes both in situ carcinoma and fibroadenoma samples). Although we were unable to detect dramatic differences in any single factor after comparing groups, we observed significant variations in several proteins that defined a specific pattern of response to surgery in invasive breast cancer patients (Table IV). We determined that, compared with noninvasive samples or healthy controls, I samples were characterized by higher preoperative concentrations of $\alpha \mathrm{FP}$, INF $\beta 1$, VEGF-A, IL18, soluble E-cadherin, CD31, factor XIIIa, VEGF-A and IL18 and lower postoperative concentrations of TNF $\alpha$ and IL5. Next, we examined the velocity of accumulation of the 42 analytes. This rate of change over time has been used to identify a signature of serum proteins associated with breast cancer relapse (26) and provides information about surgery-induced analyte dynamics regardless of the initial concentration of each protein. Following this approach, we compared the velocities of each analyte between I and B as well as between I and nI, and we detected significant differences in the velocities of VEGF-A and IL-16 (Table V). We also observed a decrease in the velocity of endoglin accumulation in I compared with $B$ and a decrease in the velocity of IL24 accumulation in I compared with nI. 

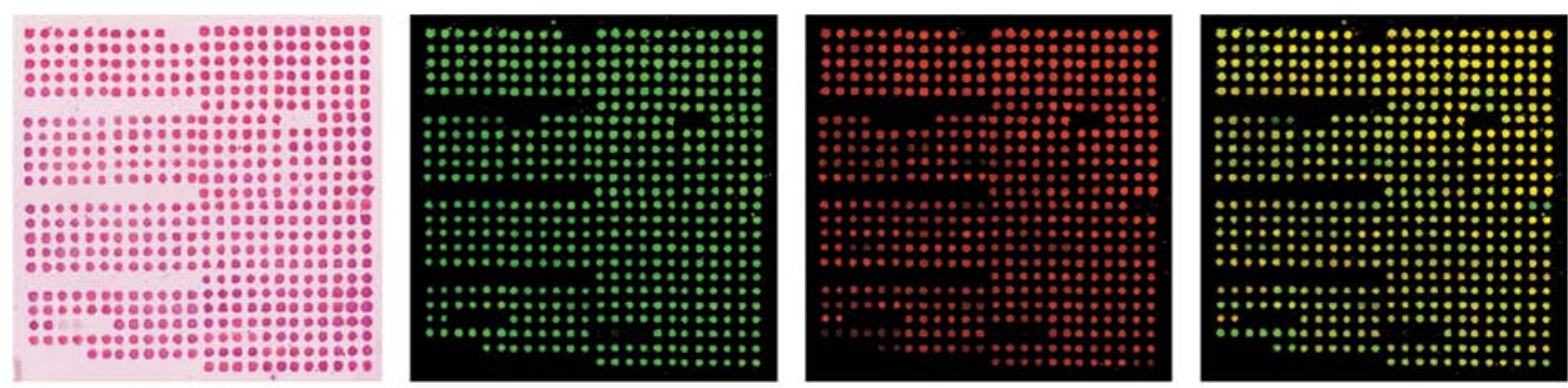

Figure 1. Reverse phase protein array (RPPA). Representative image of an RPPA. Optimal printing of serum samples was checked by Ponceau S staining (left). The levels of each analyte (green) were quantified in a laser scanner and referenced to endogenous HSA (red; overlapped, yellow).

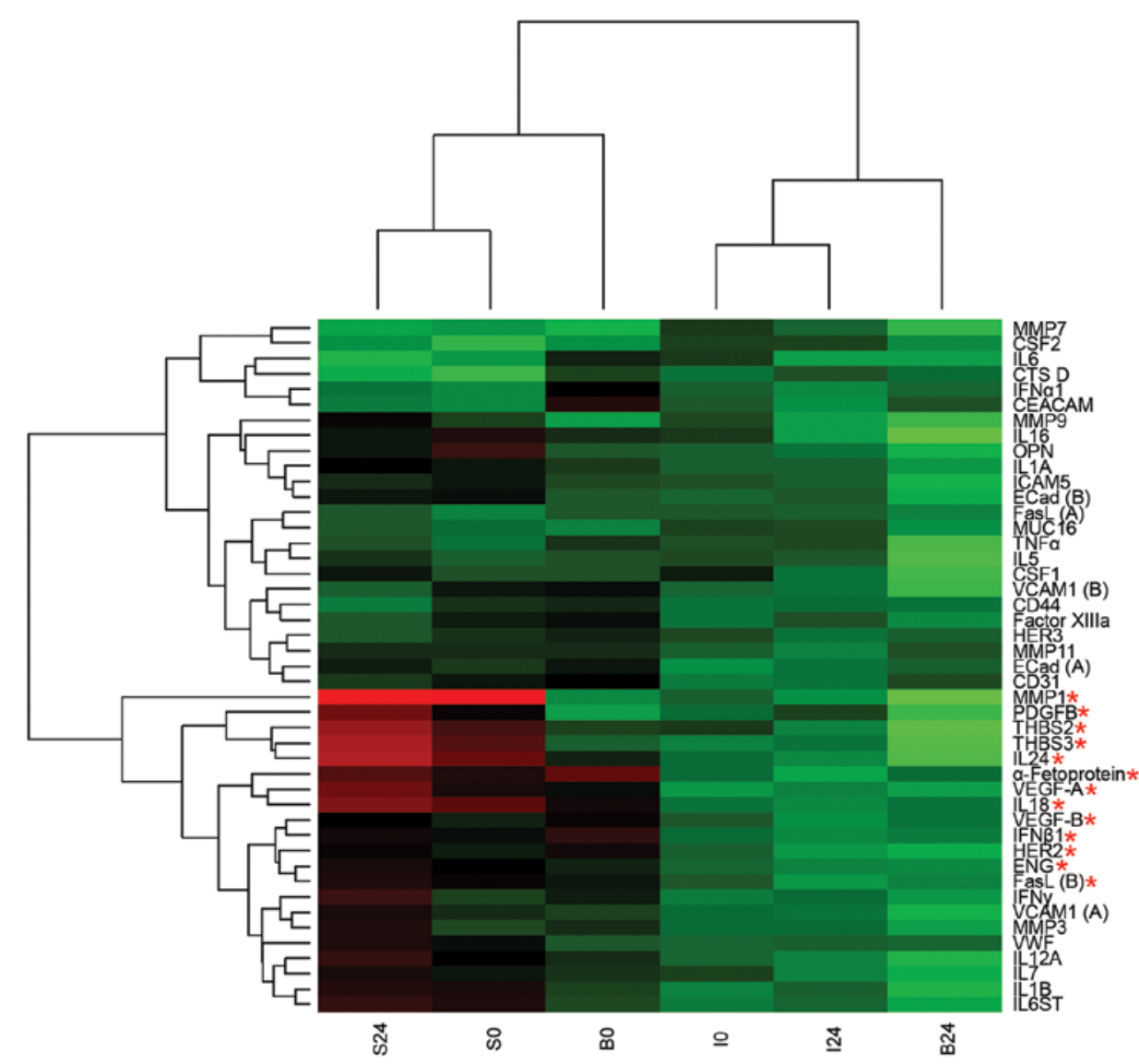

Figure 2. Serum protein profile of invasive, in situ and control groups. Unsupervised 2-way clustering of analytes and groups prior to and following surgery. Average relative levels are represented. Red boxes indicate lower concentrations and green boxes indicate higher concentrations. The set of proteins whose expression defined the groups B0-S0-S24 and B24-I0-I24 is marked with red asterisks.

\section{Discussion}

Wound healing is a highly dynamic process that is classically defined by three overlapping stages: inflammation, tissue formation and tissue remodeling (27). These stages involve many different cells, soluble factors and extracellular matrix molecules that possess critical roles in tissue repair, formation of new blood vessels and maintenance of homeostasis. Furthermore, these factors act as chemoattractants to recruit white blood cells from the bloodstream and promote a systemic response. Similarly, surgical lesions activate the release of inflammatory and angiogenic mediators that trigger the wound healing response. With regard to cancer, the impact of surgery on serum factor dynamics is of particular interest due to its involvement in the escape from dormancy and cancer recurrence. In this study, we have gained insight into the effect of breast surgery on the expression of 42 serum proteins and focused on the differential behavior that these factors display between breast cancer patients and healthy controls during the first $24 \mathrm{~h}$ following surgery.

In healthy women, the concentration of most of the analyzed proteins increased after surgery. However, only a few of them were commonly elevated in both controls and patients. Some of these changes were expected, such as increased IL6 and 
Table III. Changes after surgery in the overall population.

\begin{tabular}{lc}
\hline Soluble factor & Variation after surgery $(\%)$ \\
\hline IL16 & $11.9^{*}$ \\
IL6 & $10.1^{*}$ \\
CSF1 & 8.4 \\
THBS2 & 7.9 \\
HER2 & 7.2 \\
VEGF-B & 6.3 \\
IL7 & 6.2 \\
FasL & 6.2
\end{tabular}

*Factors with an adjusted p-value $<0.05$.

Table IV. Surgery-induced variations among groups.

\begin{tabular}{lccccc}
\hline & \multicolumn{2}{c}{ I vs. B $(\%)$} & & \multicolumn{2}{c}{ I vs. nI $(\%)$} \\
\cline { 2 - 3 } \cline { 5 - 6 } Soluble factor & $\mathrm{t}(0)$ & $\mathrm{t}(24)$ & $\mathrm{t}(0)$ & $\mathrm{t}(24)$ \\
\hline MMP7 & -10.6 & -8.2 & $-9.7^{*}$ & -7.5 \\
$\alpha$ FP & 21.8 & - & 19.3 & - \\
IFN $\beta 1$ & 15.8 & - & 14.1 & - \\
VEGF-A & 14.2 & - & $15.1^{*}$ & - \\
IL18 & 12.9 & - & $15.5^{*}$ & 9.6 \\
E-Cad (A) & 12.1 & - & 10.9 & - \\
CD31 & 12.1 & - & 11.5 & - \\
Factor XIIIa & 10.7 & - & 10.1 & - \\
IL24 & - & - & 12.3 & - \\
CSF2 & - & - & -7.9 & -6.9 \\
CD44 & - & - & 7.1 & - \\
TNF $\alpha$ & - & -12.7 & - & -9.2 \\
IL5 & - & -11.4 & - & -7.0 \\
PDGF-B & - & -11.8 & - & - \\
\hline
\end{tabular}

*Factors with adjusted p-value $<0.05$; - not significant.

Table V. Surgery-induced changes in analyte velocities.

\begin{tabular}{lcc}
\hline Soluble factor & $\operatorname{logFC}$ I vs. B & $\operatorname{logFC~I~vs.~nI~}$ \\
\hline IFN $\beta 1$ & 20.77 & 14.56 \\
VEGF-A & -10.60 & -9.65 \\
IL16 & 26.51 & 17.93 \\
IL24 & -4.56 & - \\
ENG & - & -11.25 \\
\hline
\end{tabular}

- Not significant.

CSF-1, due to their established role in postoperative inflammation and angiogenesis $(28,29)$. Other proteins that exhibited interesting changes in expression were THBS2, IL7 and IL16. Although THBS2 was first described as an inhibitor of both angiogenesis and tumor metastasis $(30,31)$, it is necessary for the proper regeneration of connective tissue during wound healing (32) and its serum levels rise in mice during the first 10 days after wound induction (33). IL7 is involved in skin repair (34) and enhances endothelial cell growth and migration (35). IL16 is a potent chemoattractant for white blood cells (36) and is indirectly associated with neovascularization and wound healing (37). These proteins have also been shown to participate in cancer growth and metastasis (38-40).

We also examined the effect of surgery on the protein profile of healthy women, invasive breast cancer patients and in situ carcinoma breast cancer patients. Although higher preoperative levels of most of the proteins were detected in I rather than in S or B samples, a small increase or even decrease in the expression of some of these proteins was detected after surgery when compared with B. This observation suggests that the sustained production of several factors by the tumor and the surrounding stroma could lead to a systemic desensitization that alters the response to surgery in cancer patients compared with healthy women.

Angiogenesis is an essential process in wound healing, however, it is also a hallmark of cancer (41). Vascularization is highly associated with aggressive disease, invasiveness and worse outcome; invasive tumors are often highly vascularized while in situ carcinomas are poorly vascularized. In agreement with these reports, our data indicate that the concentrations of several angiogenesis-related proteins are lower in $\mathrm{S}$ than in I. Strikingly, $\mathrm{S}$ was more similar to a preoperative B profile, while I was more similar to B after breast surgery, once the angiogenic cascade is triggered.

Several authors have used different proteomic approaches to identify cancer-related serum biomarkers. Mass spectrometry-based assays and antibody arrays have been used to detect metastasis-related signatures in the serum samples of breast cancer patients $(26,42-44)$; nevertheless, few of these studies have considered the effect of surgery on the serum proteome. Based on a MALDI-TOF analysis, Pietrowska et al examined therapy-induced changes in the serum profiles of breast cancer patients (44). In their study, serum samples from 70 early breast cancer patients who underwent surgery and then received adjuvant chemotherapy, radiotherapy or chemo-radiotherapy were analyzed before the surgery (A), 7-14 days after the surgery but before starting the adjuvant treatment (B) and 1 year after the surgery, once the treatment was finished $(C)$. Although several variations between $B$ and $\mathrm{C}$ were described, no clear differences between $\mathrm{A}$ and $\mathrm{B}$ were detected. Thus, the authors suggested that tumor resection had either minimal or no short-term influence on the serum profile dynamics of breast cancer patients. Using an antibody microarray platform, Carlsson et al recently identified a signature of distant metastasis in serum samples from 64 breast cancer patients that were collected both before surgery and 3-6 months after the removal of the primary tumor (26). These authors proposed the velocity of accumulation to be a more sensitive and informative predictor than analyte concentration at a given time. By analyzing this parameter, the authors reported a 21-protein signature associated with distant metastasis; strikingly, the velocity of accumulation of IL16 was identified as an accurate predictor within this signature, exhibiting higher values in metastatic breast cancer samples 
compared with non-metastatic breast cancer samples. The number of patients with early recurrence in our study cohort was, however, insufficient to obtain any significant conclusion. Instead, we detected higher velocities of IL16 accumulation during the first $24 \mathrm{~h}$ in I samples compared with both B and nI samples, although surgical injury increased serum IL16 levels in a cancer-independent manner. Based on these data, we suggest that IL16 may be involved in the surgery-driven escape from dormancy: not only is IL16 behavior modified as a consequence of breast surgery, but also higher IL16 velocities are observed in invasive breast cancer and, as reported by Carlsson et al, IL16 may be associated with the development of distal metastases.

Although surgical resection is the first line of treatment for solid tumors, little is known about the direct effects of surgery on the serum proteome, and even less is known about how these effects may impact disseminated cancer cells. We conducted a molecular dissection of the changes in several serum proteins during the first postoperative $24 \mathrm{~h}$. Inflammation and tissue regeneration, the two main processes occurring during this period of time, are stimulated by the production of soluble mediators that ensure a systemic response to local injury. However, we also identified specific variations in the serum protein profiles of invasive breast cancer patients. These observed changes in serum profiles may be strongly related to surgery-induced cancer relapse and, in agreement with previous studies, an interruption of dormancy in disseminated cancer foci.

\section{Acknowledgements}

The authors acknowledge support through grants from the Junta de Andalucia (0199/2006 and TIC-4026), the Fundacion Mutua Madrileña and the Spanish MINECO (TIN2010-16556).

\section{References}

1. Jemal A, Bray F, Center MM, Ferlay J, Ward E and Forman D: Global cancer statistics. CA Cancer J Clin 61: 69-90, 2011.

2. Perou CM, Sørlie T, Eisen MB, van De Rijn M, Jeffrey SS, Rees CA, Pollack JR, Ross DT, Johnsen H, Akslen LA, et al: Molecular portraits of human breast tumours. Nature 406 : 747-752, 2000.

3. Anderson WF and Matsuno R: Breast cancer heterogeneity: a mixture of at least two main types? J Natl Cancer Inst 98: 948-951, 2006.

4. Børresen-Dale AL, Sørlie T and Kristensen VN: On the molecular biology of breast cancer. Mol Oncol 4: 171-173, 2010.

5. Sørlie T, Perou CM, Tibshirani R, Aas T, Geisler S, Johnsen H, Hastie T, Eisen MB, van De Rijn M, Jeffrey SS, et al: Gene expression patterns of breast carcinomas distinguish tumor subclasses with clinical implications. Proc Natl Acad Sci USA 98: 10869-10874, 2001.

6. Baum M, Demicheli R, Hrushesky W and Retsky MW: Does surgery unfavourably perturb the 'natural history' of early breast cancer by accelerating the appearance of distant metastases? Eur J Cancer 41: 508-515, 2005.

7. Demicheli R, Retsky MW, Hrushesky WJM, Baum M and Gukas ID: The effects of surgery on tumor growth: a century of investigations. Ann Oncol 19: 1821-1828, 2008.

8. Fehm T, Mueller V, Marches R, Klein G, Gueckel B, Neubauer H, Solomayer E and Becker S: Tumor cell dormancy: implications for the biology and treatment of breast cancer. Acta Pathol Microbiol Immunol Scand 116: 742-753, 2008.

9. Tseng WW, Fadaki N and Leong SP: Metastatic tumor dormancy in cutaneous melanoma: Does surgery induce escape? Cancers 3 : 730-746, 2011.
10. Retsky MW, Demicheli R, Hrushesky W, Baum M and Gukas I: Surgery triggers outgrowth of latent distant disease in breast cancer: An inconvenient truth? Cancers 2: 305-337, 2010.

11. Uhr JW and Pantel K: Controversies in clinical cancer dormancy. Proc Natl Acad Sci USA 108: 1-5, 2011.

12. Demicheli R, Retsky MW, Hrushesky WJM and Baum M: Tumor dormancy and surgery-driven interruption of dormancy in breast cancer: learning from failures. Nat Clin Pract Oncol 4: 699-710, 2007.

13. Aguirre-Ghiso JA: Models, mechanisms and clinical evidence for cancer dormancy. Nat Rev Cancer 7: 834-846, 2007.

14. Coffey JC, Wang JH, Smith MJF, Bouchier-Hayes D, Cotter TG and Redmond HP: Excisional surgery for cancer cure: therapy at a cost. Lancet Oncol 4: 760-768, 2003.

15. Spurrier B, Honkanen P, Holway A, Kumamoto K, Terashima M, Takenoshita S, Wakabayashi G, Austin J and Nishizuka S: Protein and lysate array technologies in cancer research. Biotechnol Adv 26: 361-369, 2008.

16. Mueller C, Liotta La and Espina V: Reverse phase protein microarrays advance to use in clinical trials. Mol Oncol 4: 1-21, 2010.

17. Sheehan KM, Calvert VS, Kay EW, Lu Y, Fishman D, Espina V, Aquino J, Speer R, Araujo R, Mills GB, et al: Use of reverse phase protein microarrays and reference standard development for molecular network analysis of metastatic ovarian carcinoma. Mol Cell Proteomics 4: 346-355, 2005.

18. Tibes R, Qiu Y, Lu Y, Hennessy B, Andreeff M, Mills GB and Kornblau SM: Reverse phase protein array: validation of a novel proteomic technology and utility for analysis of primary leukemia specimens and hematopoietic stem cells. Mol Cancer Ther 5: 2512-2521, 2006.

19. Brennan DJ, O'Connor DP, Rexhepaj E, Ponten F and Gallagher WM: Antibody-based proteomics: fast-tracking molecular diagnostics in oncology. Nat Rev Cancer 10: 605-617, 2010.

20. Grote T, Siwak DR, Fritsche HA, Joy C, Mills GB, Simeone D, Whitcomb DC and Logsdon CD: Validation of reverse phase protein array for practical screening of potential biomarkers in serum and plasma: accurate detection of CA19-9 levels in pancreatic cancer. Proteomics 8: 3051-3060, 2008.

21. Holdaway IM, Lethaby AE, Mason BH, Singh V, Harman JE, MacCormick M and Civil ID: Effect of breast surgery on serum levels of insulin-like growth factors (IGF-I, IGF-II, and IGF binding protein-3) in women with benign and malignant breast lesions. Ann Surg Oncol 8: 25-31, 2001.

22. Smyth GK: Limma: linear models for microarray data. In: Bioinformatics and Computational Biology Solutions using $\mathrm{R}$ and Bioconductor. Gentleman R, Carey V, Dudoit S, Irizarry R and Huber W (eds). Springer, New York, NY, pp397-420, 2005.

23. Yang YH and Thorne NP: Normalization for two-color cDNA microarray data. Institute of Mathematical Statistics, 2003.

24. Smyth GK: Linear models and empirical bayes methods for assessing differential expression in microarray experiments. Stat Appl Gen Mol Biol 3: Article3, Feb 12, 2004 (Epub ahead of print).

25. Benjamini Y and Hochberg Y: Controlling the false discovery rate: A practical and powerful approach to multiple testing. J Roy Stat Soc Ser B (Stat Method) 57: 289-300, 1995.

26. Carlsson A, Wingren C, Kristensson M, Rose C, Fernö M, Olsson H, Jernström H, Ek S, Gustavsson E, Ingvar C, et al: Molecular serum portraits in patients with primary breast cancer predict the development of distant metastases. Proc Natl Acad Sci USA 108: 14252-14257, 2011.

27. Gurtner GC, Werner S, Barrandon Y and Longaker MT: Wound repair and regeneration. Nature 453: 314-321, 2008.

28. Hamilton JA: Colony-stimulating factors in inflammation and autoimmunity. Nat Rev Immunol 8: 533-544, 2008.

29. Lin Z-Q, Kondo T, Ishida Y, Takayasu T and Mukaida N: Essential involvement of IL-6 in the skin wound-healing process as evidenced by delayed wound healing in IL-6-deficient mice. J Leukoc Biol 73: 713-721, 2003.

30. Oshika Y, Masuda K, Tokunaga T, Hatanaka H, Kamiya T, Abe Y, Ozeki Y, Kijima H, Yamazaki H, Tamaoki N, et al: Thrombospondin 2 gene expression is correlated with decreased vascularity in non-small cell lung cancer. Clin Cancer Res 4: 1785-1788, 1998.

31. Tokunaga T, Nakamura M, Oshika Y, Abe Y, Ozeki Y, Fukushima Y, Hatanaka H, Sadahiro S, Kijima H, Tsuchida T, et al: Thrombospondin 2 expression is correlated with inhibition of angiogenesis and metastasis of colon cancer. $\mathrm{Br} \mathrm{J} \mathrm{Cancer} \mathrm{79:}$ 354-359, 1999. 
32. Maclauchlan S, Skokos EA, Agah A, Zeng J, Tian W, Davidson JM, Bornstein P and Kyriakides TR: Enhanced angiogenesis and reduced contraction in thrombospondin-2-null wounds is associated with increased levels of matrix metalloproteinases-2 and -9, and soluble VEGF. J Histochem Cytochem 57: 301-313, 2009.

33. Kyriakides TR, Tam JW and Bornstein P: Accelerated wound healing in mice with a disruption of the thrombospondin 2 gene. J Invest Dermatol 113: 782-787, 1999.

34. Jameson J and Havran WL: Skin gammadelta T-cell functions in homeostasis and wound healing. Immunol Rev 215: 114-122, 2007.

35. Al-Rawi MAA, Watkins G, Mansel RE and Jiang WG: The effects of interleukin-7 on the lymphangiogenic properties of human endothelial cells. Int J Oncol 27: 721-730, 2005.

36. Cruikshank W and Little F: lnterleukin-16: the ins and outs of regulating T-cell activation. Crit Rev Immunol 28: 467-483, 2008.

37. Stabile E, Kinnaird T, la Sala A, Hanson SK, Watkins C, Campia U, Shou M, Zbinden S, Fuchs S, Kornfeld H, et al: CD8 ${ }^{+}$ $\mathrm{T}$ lymphocytes regulate the arteriogenic response to ischemia by infiltrating the site of collateral vessel development and recruiting $\mathrm{CD}^{+}$mononuclear cells through the expression of interleukin-16. Circulation 113: 118-124, 2006.

38. Al-Rawi MAA, Rmali K, Watkins G, Mansel RE and Jiang WG: Aberrant expression of interleukin-7 (IL-7) and its signalling complex in human breast cancer. Eur J Cancer 40: 494-502, 2004.
39. Germano G, Allavena P and Mantovani A: Cytokines as a key component of cancer-related inflammation. Cytokine 43: 374-379, 2008.

40. Studebaker AW, Storci G, Werbeck JL, Sansone P, Sasser AK, Tavolari S, Huang T, Chan MWY, Marini FC, Rosol TJ, et al: Fibroblasts isolated from common sites of breast cancer metastasis enhance cancer cell growth rates and invasiveness in an interleukin-6-dependent manner. Cancer Res 68: 9087-9095, 2008.

41. Hanahan D and Weinberg RA: The hallmarks of cancer. Cell 100: 57-70, 2000

42. Carlsson A, Wingren C, Ingvarsson J,Ellmark P,Borrebaeck CAK, Baldertorp B, Fernö M and Olsson H: Serum proteome profiling of metastatic breast cancer using recombinant antibody microarrays. Eur J Cancer 44: 472-480, 2008.

43. Gast M-CW, Zapatka M, van Tinteren H, Bontenbal M, Span PN, Tjan-Heijnen VCG, Knol JC, Jimenez CR, Schellens JHM and Beijnen JH: Postoperative serum proteomic profiles may predict recurrence-free survival in high-risk primary breast cancer. J Cancer Res Clin Oncol 137: 1773-1783, 2011.

44. Pietrowska M, Polanska J, Marczak L, Behrendt K, Nowicka E, Stobiecki M, Polanski A, Tarnawski R and Widlak P: Mass spectrometry-based analysis of therapy-related changes in serum proteome patterns of patients with early-stage breast cancer. J Transl Med 8: 66, 2010. 